\title{
Timbulan dan Reduksi Sampah di Kecamatan Sukun Kota Malang
}

\author{
Siti Sholikah dan Welly Herumurti \\ Departemen Teknik Lingkungan, Fakultas Teknik Sipil dan Perencanaan (FTSP), Institut Teknologi \\ Sepuluh Nopember (ITS) \\ e-mail: herumurti@enviro.its.ac.id
}

\begin{abstract}
Abstrak-Sampah rumah tangga merupakan salah satu masalah yang perlu mendapatkan perhatian serius karena jumlah timbulan sampah yang senantiasa meningkat. Komposisi sampah perlu diketahui untuk menentukan pengelolaan sampah, salah satu pengelolaan sampah yakni reduksi sampah. Besarnya timbulan sampah dapat dikurangi dengan melakukan reduksi sampah disumber, salah satunya melalui Bank Sampah. Pada penelitian ini dilakukan perhitungan timbulan sampah dan komposisi sampah. Kecamatan Sukun dipilih karena memiliki jumlah Bank Sampah paling banyak di Kota Malang yakni 82 unit Bank Sampah. Skenario yang digunakan yaitu skenario pengumpulan sampah melalui TPS (kondisi tidak ideal), pengumpulan sampah oleh Bank Sampah (kondisi eksisting), pengumpulan sampah oleh Bank Sampah eksisting dan sektor informal, pengumpulan sampah oleh Bank Sampah optimasi dan sektor informal. Data primer dan sekunder berupa timbulan sampah, komposisi sampah, kondisi eksisting Bank Sampah, dan reduksi dari Bank Sampah. Data primer didapatkan melalui sampling di TPS dan kuisoner di Bank Sampah. Sedangkan data sekunder didapatkan dari Kantor Kecamatan Sukun, Dinas Lingkungan Hidup Kota Malang, BPS Kota Malang, dan Bank Sampah Malang. Kecamatan Sukun memiliki Laju timbulan sampah rumah tangga sebesar $0,4 \mathrm{~kg} /$ orang.hari. Laju timbulan sampah dengan area Bank Sampah sebesar 0,33 kg/orang.hari. Komposisi sampah sejenis sampah rumah tangga terdiri dari, dapat dikomposkan $67,82 \%$, plastik $8,82 \%$, kertas $10,88 \%$, kain $1,26 \%$, logam $1,27 \%$, kayu $0,9 \%$, kaca $0,1 \%$, diapers $5,42 \%$, B3 $1,3 \%$, karet $0,1 \%$ dan lainnya $0,1,92 \%$. Reduksi dari Bank Sampah dapat mengurangi timbulan sampah sebesar 0,14 kg/orang/hari. Timbulan sampah tanpa adanya Bank Sampah di Kecamatan Sukun Sebesar 66,6 ton/hari, dengan adanya Bank Sampah timbulan sebesar 65,9 ton/hari.
\end{abstract}

Kata Kunci- Bank Sampah, Komposisi, Pengelolaan Sampah, Reduksi, Timbulan.

\section{PENDAHULUAN}

$\mathrm{S}_{\mathrm{p}}^{\mathrm{A}}$ AMPAH perkotaan merupakan salah satu masalah yang perlu mendapatkan perhatian serius. Sampah telah menjadi permasalahan nasional sehingga pengelolaannya perlu dilakukan secara komprehensif dan terpadu dari hulu ke hilir agar memberikan manfaat secara ekonomi, sehat bagi masyarakat, dan aman bagi lingkungan serta dapat mengubah perilaku masyarakat [1]. Kota Malang merupakan kota terbesar kedua di Jawa Timur. Jumlah penduduk di Kota Malang 895.338 jiwa dengan luas wilayah $110.056 \mathrm{~km}^{2}$. Kota Malang terdiri atas 5 Kecamatan yaitu Kedung kandang, Klojen, Blimbing, Lowokwaru, dan Sukun serta 57 kelurahan [2] Menurut Dinas Kebersihan dan Pertamanan, pada tahun
2009 timbulan sampah di Kota Malang $1.067 \mathrm{~m}^{3} /$ hari dan volume sampah yang terangkut ke TPA $785 \mathrm{~m}^{3} / \mathrm{hari}$ atau 73,6\% [3].Sedangkan timbulan sampah di Kecamatan Sukun dari Januari hingga September $2015220 \mathrm{~m}^{3}$ /hari [4]. Jumlah penduduk di Kecamatan Sukun 191.229 jiwa [2]. Kecamatan Sukun merupakan penghasil sampah terbesar di Malang, dengan menghasilkan sampah sebesar $217,12 \mathrm{~m}^{3}$ atau $6,07 \%$ dari jumlah sampah diseluruh Malang. Hal ini disebabkan jumlah penduduk yang besar dengan wilayah relatif sempit [1]. Pengurangan timbulan sampah di Kota Malang bisa dilakukan dengan melalui Bank Sampah Malang. Bank Sampah bisa mengurangi timbulan sampah di sumber hingga $0,24 \mathrm{~kg} /$ orang.hari [5]. Reduksi sampah di sumber akan mengurangi jumlah timbulan sampah dan pengumpulan sampah.

\section{METODE PENELITIAN}

\section{A. Penentuan Wilayah Penelitian}

Penentuan wilayah penelitian ini didasarkan pada pemetaan area pelayanan sampah di masing-masing TPS ataupun random sampling. Random sampling dilakukan dengan pemilihan secara acak. Pengambilan data sampling meliputi timbulan, komposisi dan densitas sampah rumah tangga. Penentuan wilayah penelitian juga dilakukan dengan pengamatan langsung dan informasi yang diperoleh dari instansi pemerintah, seperti kantor kecamatan dan Badan Pusat Statistik, mengenai kondisi eksisting daerah dan kependudukan pada lokasi studi.

Pembagian lokasi sampling dilakukan pada 2 kelurahan dengan 3 kategori, yaitu nasabah bank sampah, non nasabah tetapi di RW yang mempunyai Bank Sampah, dan non nasabah di kelurahan yang mempunyai sedikit Bank Sampah. Kategori ditujukan untuk menentukan seberapa besar pengaruh Bank Sampah terhadap timbulan dan reduksi sampah di Kecamatan Sukun. Penentuan jumlah sampel sampah yang akan diambil menggunakan metode SNI 193964-1994. Sehingga pembagian kategori dapat dilihat pada Tabel 1. 
Tabel 1.

Jumlah sampel yang diambil di Kecamatan Sukun

\begin{tabular}{lc}
\hline \hline Kategori & Jumlah KK \\
\hline Nasabah Bank Sampah & 50 \\
Non nasabah tetapi di RW yang mempunyai & 25 \\
Bank Sampah & \\
Non nasabah di kelurahan yang mempunyai & 25 \\
sedikit Bank Sampah & $\mathbf{1 0 0}$ \\
Total & \\
\hline \hline
\end{tabular}

\section{B. Pengukuran Timbulan, dan Komposisi}

Pengukuran timbulan sampah rumah tangga dilakukan dengan menggunakan metode Load-count yaitu sampah yang dikumpulkan oleh petugas gerobak dari sumber kemudian ditimbang satu gerobak sehingga diketahui masa sampah yang dihasilkan. Pengambilan sampel timbulan dilakukan selama 8 hari. Perhitungan densitas tiap komposisi sapah digunakan kotak densitas 40L sesuai dengan SNI 19-3964-1994. Densitas total diperoleh dari massa sampah yang ditimbang dalam satu gerobak dibagi dengan volume sampah pada gerobak. Sampah yang dihasilkan diambil sebanyak $100 \mathrm{~kg}$ untuk dihitung komposisi sampah rumah tangga. Karakteristik sampah yang diukur meliputi volume, densitas, dan komposisi sampah. Volume sampah diperoleh dari hasil pengukuran terhadap volume sampah pada tiap gerobak yang masuk ke TPS di Kecamatan Sukun. Melalui data tersebut, selanjutnya dapat dihitung densitas sampah. Densitas sampah yang dihitung adalah densitas sampah di gerobak TPS dan densitas sampah di truk menuju TPA. Persamaan untuk menghitung timbulan dan densitas sampah dapat dilihat pada persamaan 1 dan 2 .

Massa Sampah per Hari

Frekuensi pengambilan X Jumlah pendudul

Densitas Sampah $\left(\mathrm{kg} / \mathrm{m}^{3}\right)=\frac{\text { Berat Sampah }(\mathrm{kg})}{\text { Volume sampah }\left(\mathrm{m}^{3}\right)}$

Selain itu, komposisi sampah yang dianalisis berdasarkan hasil sampling dapat diklasifikasikan dan digambarkan melalui diagram. Perhitungan persentase komposisi digunakan rumus 2 sebagai berikut:

Komposisi sampah (\%) $=\frac{\text { Jenis sampah }(\mathrm{kg})}{\text { Berat sampah }(100 \mathrm{~kg})} \times 100 \%$.

\section{Reduksi Sampah dari Bank Sampah}

Reduksi sampah pemukiman dapat dianalisis berdasarkan hasil survei terhadap pengelolaan sampah berbasis masyarakat di Kecamatan Sukun, seperti Bank Sampah dan sektor informal (pengepul).Reduksi sampah dari Bank Sampah dapat diketahui dari jumlah dan komposisi sampah yang masuk dalam jangka waktu tertentu dalam satuan $\mathrm{kg} / \mathrm{hari}$ dan dari hasil wawancara dan mengikuti kegiatan penimbangan yang dilakukan masyarakat dalam jangka waktu tertentu. Reduksi sampah dinyatakan dalam satuan berat $(\mathrm{kg} / \mathrm{hari})$. Reduksi sampah di pemukiman bisa dilakukan dari sumber sampah, yakni menghitung hasil pilahan dari tiap sumber. Pengukuran reduksi sampah juga dilakukan di TPS. Untuk mengukur timbulan sampah setelah dilakukan reduksi melalui berbagai pengelolaan, dilakukan penimbangan massa sampah yang dipilah oleh setiap petugas gerobak (yang melakukan pemilahan) dan hasil pilahan (pengepul, pemulung) di setiap TPS selama 2-3 hari kemudian dirata-rata.

\section{HASIL DAN PEMBAHASAN}

\section{A. Timbulan dan Komposisi Sampah}

Lokasi penelitian yang dipilih yakni timbulan dari petugas gerobak yang melewati area terlayani Bank Sampah dan timbulan dari area yang tidak ada Bank Sampah. Hasil pengukuran timbulan sampah sampah di TPS menunjukkan banyaknya sampah yang dihasilkan setelah dilakukan reduksi. Pengukuran timbulan sampah di TPS bertujuan untuk mengetahui timbulan sampah setelah dilakukan reduksi melalui berbagai pengelolaan sampah yang ada di Kecamatan. Reduksi ini berasal dari sumber dengan adanya bank sampah, reduksi yang dilakukan petugas gerobak yang melakukan pemilahan dan reduksi dari pemulung yang memilah sampah di TPS.

Pengukuran timbulan sampah dilakukan selama 8 hari. Sampah ditimbang dari masing-masing rumah yang dilalui oleh petugas gerobak. Perhitungan timbulan sampah per hari yaitu membagi jumlah sampah $(\mathrm{kg})$ dengan frekuensi pengambilan sampah dan jumlah penduduk yang mengumpulkan sampah. Berdasarkan hasil pengukuran, timbulan sampah tiap area berbeda-beda sesuai kapasitasnya. Hasil perhitungan timbulan sampah dapat dilihat pada Tabel 2. Persamaan untuk menghitung timbulan sampah dapat dilihat pada persamaan 3 .

Contoh perhitungan timbulan sampah yakni :

- Massa sampah hari ke - $1 \quad: 210,45 \mathrm{~kg}$

- Frekuensi pengambilan : 2 hari sekali

- Jumlah penduduk (orang) : 444 orang

- Timbulan sampah :

$$
\begin{gathered}
\frac{\text { Massa Sampah per Hari }}{\text { Frekuensi pengambilan X Jumlah pendudul }}=\frac{210,45}{2 \mathrm{X} 444}=0,24 \mathrm{~kg} / \mathrm{orang} / \mathrm{hari} \\
\text { Tabel } 2 \\
\text { Timbulan Sampah di Tiap TPS di Kecamatan Sukun }
\end{gathered}
$$

\begin{tabular}{cccc}
\hline \hline $\begin{array}{c}\text { Jumlah } \\
\text { Penduduk } \\
\text { (orang) }\end{array}$ & Hari Sekali & Massa (kg) & $\begin{array}{c}\text { Laju Timbulan } \\
\text { (kg/orang/hari) }\end{array}$ \\
\hline 444 & 2 & 210,45 & 0,24 \\
259 & 2 & 86,05 & 0,17 \\
477 & 2 & 420,42 & 0,44 \\
211 & 2 & 410,49 & 0,97 \\
414 & 1 & 134,03 & 0,32 \\
522 & 2 & 340,85 & 0,33 \\
414 & 1 & 157,486 & 0,38 \\
422 & 1 & 173,556 & 0,41 \\
Laju Timbulan Rata-rata (kg/orang.hari) & 0,40 \\
\hline \hline
\end{tabular}

Jumlah timbulan sampah di TPS berbeda-beda. Hal ini dipengaruhi oleh area pelayanan, jumlah penduduk dan adanya reduksi. Area pelayanan yang luas membuat timbulan sampah yang dihasilkan semakin banyak. Hal ini karena area pelayanan yang luas memiliki jumlah penduduk yang banyak sehingga timbulan yang dihasilkan juga semakin banyak. Reduksi sampah yang dilakukan warga area TPS juga mempengaruhi, semakin banyaknya warga yang menjadi nasabah Bank Sampah semakin banyak juga sampah yang direduksi.

Jumlah penduduk di Kecamatan Sukun 191.229 jiwa, dengan kepadatan penduduk kurang dari 100 jiwa per Ha. [2]. Hasil laju timbulan yang diperoleh dari pengukuran langsung 
jika dibandingkan dengan SNI 19-3983-1995 tentang spesifikasi timbulan sampah untuk kota kecil dan kota sedang di Indonesia memiliki perbedaan tidak begitu jauh. Laju timbulan rata-rata sebesar 0,4 kg/orang.hari. Malang merupakan kategori Kota sedang. Timbulan sampah untuk kota sedang berdasarkan SNI sebesar 0,3-0,4 kg/orang.hari. Sehingga apabila laju timbulan sampah dibandingkan dengan SNI, nilainya berada direntang SNI.

Komposisi sampah didapatkan dengan pemilahan timbulan sampah di TPS. Pemilahan sampah berdasarkan beberapa macam, antara lain plastik, dapat dikomposkan, kertas, logam, kaca, kain, karet, kayu, diapers, B3 dan lainnya. Komposisi sampah merupakan persentase dari jumlah sampah masingmasing jenis dibagi dengan total sampah. Komposisi hasil pilahan di TPS dapat dilihat pada Tabel 3.

Tabel 3.

Komposisi Sampah di Kecamatan Sukun

\begin{tabular}{cc}
\hline \hline Komposisi Sampah & Persentase \\
\hline Dapat Dikomposkan & $67,82 \%$ \\
Kertas & $10,88 \%$ \\
Plastik & $8,82 \%$ \\
Logam & $1,27 \%$ \\
Kaca & $0,10 \%$ \\
Kain & $1,26 \%$ \\
Karet & $0,10 \%$ \\
Kayu & $0,90 \%$ \\
Diapers & $5,42 \%$ \\
B3 & $1,30 \%$ \\
Lainnya & $1,92 \%$ \\
Total & $100 \%$ \\
\hline
\end{tabular}

Jenis sampah yang paling banyak dihasilkan yakni sampah yang dapat dikomposkan. Sampah sisa makanan dari rumah didominasi oleh sampah dapat dikomposkan, yakni sampah sisa makanan karena kebutuhan yang ada setiap hari. Sampah plastik dan kertas memiliki persentase terbesar kedua dan ketiga. Hal ini menunjukkan masih banyak masyarakat yang belum memanfaatkan sampah plastik dan kertas untuk ditabung di Bank Sampah. Beberapa jenis sampah pada komposisi sampah masih ada yang harus diklasifikasikan menjadi beberapa macam sampah yang lebih spesifik.

\section{B. Reduksi Sampah}

Reduksi sampah disumber dilakukan oleh masyarakat melalui Bank Sampah. Jumlah sampah yang direduksi berdasarkan tiap jenisnya dari beberapa bank sampah kemudian ditentukan rata-ratanya. Reduksi bank sampah di Kecamatan Sukun sebesar 0,14 kg/orang/hari. Jenis sampah yang direduksi diantaranya kertas, plastik, logam dank kaca. Kertas mempunyai komposisi sampah paling besar yaitu sebesar 56,8\%. Persentase reduksi eksisting dari Bank Sampah adalah sebesar $1 \%$.

Massa sampah di tiap Bank Sampah berbeda-beda. Hal ini dikarenakan jumlah nasabah tiap Bank Sampah berbeda-beda dan jumlah sampah yang dihasilkan tiap nasabah berbedabeda. Secara garis besar sampah yang dijual ke Bank Sampah yakni sampah plastik, kertas, logam, kaca dan alumunium. Besarnya reduksi sampah per nasabah yakni 0,14 $\mathrm{kg} /$ orang/hari. Nilai ini didapat berdasarkan rata-rata reduksi sampah tiap Kelurahan. Reduksi sampah setiap Kelurahan berbeda-beda. Besarnya nilai reduksi dipengaruhi jumlah nasabah Bank Sampah per Kelurahan dikalikan dengan hasil pilahan yang ditabung rata-rata satu bulan sekali. Data reduksi sampah per nasabah dapat dilihat pada Tabel 4.

Tabel 4.

Reduksi Sampah per Nasabah

\begin{tabular}{cccccc}
\hline \hline $\begin{array}{c}\text { Bank } \\
\text { Sampah }\end{array}$ & RT & RW & $\begin{array}{c}\text { Jumlah } \\
\text { Nasabah } \\
\text { (KK) }\end{array}$ & $\begin{array}{c}\text { kg / } \\
\text { bulan }\end{array}$ & kg/orang.hari \\
\hline M-521 & 10 & 6 & 20 & 181,05 & 0,08 \\
M-123 & 5 & 2 & 15 & 170,23 & 0,10 \\
M-294 & 6 & 5 & 10 & 261,26 & 0,24 \\
M-366 & 10 & 3 & 9 & 153,68 & 0,15 \\
M-183 & 3 & 3 & 17 & 301,45 & 0,16 \\
M-254 & 4 & 1 & 13 & 184,42 & 0,13 \\
& Total & & 14,00 & 208,68 & 0,14 \\
\hline \hline
\end{tabular}

Reduksi sebesar 0,14 kg/orang/hari, membuat timbulan sampah di setiap Kelurahan mengalami penurunan. Dari reduksi tersebut sampah kertas memiliki jumlah komposisi terbanyak yang masuk ke Bank Sampah di bandingkan jenis lainnya. Tabel persentase komposisi sampah yang masuk ke Bank Sampah dapat dilihat pada Tabel 5.

Tabel 5.

Komposisi Sampah di Bank Sampah

\begin{tabular}{ccc}
\hline \hline Jenis Sampah & Timbulan Sampah (kg/hari) & Komposisi \\
\hline Kertas & 3,50 & $56,8 \%$ \\
Plastik & 1,70 & $27,6 \%$ \\
Logam & 0,4 & $6,5 \%$ \\
Kaleng & 0,54 & $8,8 \%$ \\
Kaca & 0,02 & $0,3 \%$ \\
Total & 6,16 & $100,0 \%$ \\
\hline
\end{tabular}

Berdasarkan Tabel 5 sampah kertas merupakan komposisi sampah paling banyak yang masuk ke Bank Sampah. Hal ini dikarenakan jumlah sampah kertas merupakan sampah yang paling banyak dibanding sampah plastik, logam dan lainnya. Selain itu sampah kertas memiliki nilai jual yang lebih tinggi dibanding lainnya kecuali sampah logam. Sampah logam memiliki nilai jual tertinggi tetapi jumlah dari sampah logam itu sendiri hanya sedikit. Jumlah sampah yang direduksi dipengaruhi oleh kebiasaan masyarakat, jenis aktifitas, jenis kota yang merupakan kota sedang dimana penggunaan plastik lebih kecil dibandingkan dengan kota besar, perekonomian masyarakat menengah ke atas atau menengah kebawah, dan lokasi dengan keberadaan pabrik plastik.

Data hasil reduksi masing-masing Kelurahan dapat dilihat pada Tabel 6.

Tabel 6.

Reduksi per Kelurahan dengan Bank Sampah

\begin{tabular}{cccc}
\hline \hline Kelurahan & $\begin{array}{c}\text { Reduksi BS } \\
\text { (kg/or.hari) }\end{array}$ & $\begin{array}{c}\text { Timbulan } \\
\text { sampah } \\
\text { (kg/hari) }\end{array}$ & $\begin{array}{c}\text { Reduksi BS } \\
\text { eksisting } \\
\text { (kg/hari) }\end{array}$ \\
\hline Sukun & 0,14 & 6533 & 192 \\
Mulyorejo & 0,14 & 4799 & 35 \\
Bandungrejosari & 0,14 & 9508 & 39 \\
Pisang Candi & 0,14 & 4803 & 17 \\
Tanjungrejo & 0,14 & 9964 & 55 \\
Bandulan & 0,14 & 5047 & 74 \\
Karangbesuki & 0,14 & 5796 & 30 \\
Cipto Mulyo & 0,14 & 5539 & 91 \\
Gadang & 0,14 & 6937 & 33 \\
Kebonsari & 0,14 & 3439 & 32 \\
Bakalan Krajan & 0,14 & 4250 & 26 \\
\hline \hline
\end{tabular}

Pengukuran reduksi oleh petugas pengumpul sampah dilakukan disetiap TPS di Kecamatan Sukun. Total timbulan 
sampah rumah tangga di Kecamatan Sukun yang menuju TPS sebelum di reduksi adalah sebesar 66,6 ton/hari., dan setelah direduksi timbulan sampah sebesar 65,9 ton/hari. Reduksi sampah yang dilakukan di TPS di Kecamatan Sukun sebesar $1.333 \mathrm{~kg}$ per hari oleh sektor informal (petugas pengumpul gerobak dan pengepul). Berat pemilahan yang didapat pemulung di TPS sebesar $845 \mathrm{~kg}$. Sedangkan berat pilahan dari petugas gerobak sebesar $489 \mathrm{~kg}$. Reduksi sampah yang dilakukan oleh petugas gerobak dan pemulung di TPS juga mempengaruhi timbulan sampah di Kecamatan Sukun. Setiap TPS di rata-rata memiliki 1 hingga 2 orang pemulung. Petugas gerobak yang memilah sampah biasannya dilakukan di TPS atau selama proses pengumpulan sampah. Data jumlah reduksi didapatkan dengan menimbang hasil pilahan dari petugas gerobak. Total reduksi sampah dari sektor informal hasilnya dapat dilihat pada Tabel 7 .

Tabel 7.

Total Reduksi Sampah dari Sektor Informal

\begin{tabular}{llll}
\hline \hline TPS & $\begin{array}{l}\text { Petugas } \\
\text { Gerobak }(\mathbf{k g})\end{array}$ & $\begin{array}{l}\text { Pemulung } \\
\text { TPS }(\mathbf{k g})\end{array}$ & $\begin{array}{l}\text { Total } \\
(\mathbf{k g})\end{array}$ \\
\hline Keben & 83,5 & 64,3 & 147,8 \\
Manyar & 70,3 & 160,8 & 231,1 \\
Klayatan & 22,5 & 14,1 & 36,6 \\
Comboran & 13,0 & 150,0 & 163,0 \\
Kemantren & 17,8 & 27,0 & 44,8 \\
Bentoel & 27,8 & 25,0 & 52,8 \\
Raya Langsep & 42,8 & 48,5 & 91,3 \\
Tidar & 3,3 & 39,4 & 42,7 \\
Gasek & 56,1 & 15,9 & 72,0 \\
Bakalan & 21,1 & 60,0 & 81,1 \\
Klabang & 23,1 & 40,3 & 63,4 \\
Bandulan & 49,0 & 32,5 & 81,5 \\
Tanjung & 16,5 & 27,8 & 44,3 \\
Terminal Mulyorejo & 19,1 & 51,0 & 70,1 \\
Istana Dieng & 22,1 & 88,0 & 110,1 \\
Jumlah & 488,1 & 844,6 & 1332,6 \\
\hline \hline
\end{tabular}

Reduksi sampah di TPS Manyar memiliki nilai paling banyak yakni 231,1 kg/hari. Dari 52 ritasi gerobak yang masuk, tidak semua petugas gerobak melakukan reduksi. Sehingga jumlah reduksi yang dihasilkan tidak terlalu signifikan. Terdapat dua jenis sektor informal, yakni para pemulung di TPS dan petugas gerobak di TPS yang melakukan pemilahan tiap harinya. Jenis pilahan yang mereka hasilkan merupakan campuran, yakni jenis sampah kertas, plastik kresek, botol plastik dan plastik gelas. Mereka ketika di TPS memilah tidak sesuai dengan jenis masing-masing sampah, tetapi ketika di rumah mereka melakukan pemilahan kembali. Berat pemilahan yang didapat pemulung di TPS sebesar 844,6 kg. Sedangkan berat pilahan dari petugas gerobak sebesar $488,1 \mathrm{~kg}$.

Aktifitas pengelolaan sampah pada sektor informal seperti daur ulang dilakukan oleh pemulung dan petugas gerobak.
Jenis barang lapak atau sampah yang dipilah adalah sampah plastik seperti botol plastik; kantong kresek, plastik keras, bak, tutup botol/galon, sampah kertas seperti HVS, karton, kardus, koran,majalah; sampah logam, kaca dan karet. Tabel persentase komposisi hasil reduksi dari sektor informal dapat dilihat pada Tabel 8 .

Tabel 8.

Persentase Komposisi Reduksi Sektor Informal

\begin{tabular}{lll}
\hline \hline Jenis Sampah & Timbulan Sampah (kg/hari) & Komposisi \\
\hline Kertas & 698,82 & $52 \%$ \\
Plastik & 521,90 & $39 \%$ \\
Logam & 89,12 & $7 \%$ \\
Kaleng & 10,40 & $1 \%$ \\
Kaca & 11,75 & $1 \%$ \\
Total & 1332,00 & $100 \%$ \\
\hline \hline
\end{tabular}

Berdasarkan data pada Tabel 8 jumlah reduksi sampah terbesar pada jenis sampah kertas. Sampah kertas yang dipilah oleh petugas pengumpul diantarnya kertas karton, kardus, dan duplek/HVS. Hal ini karena sampah kertas memiliki jumlah sampah paling banyak dan memiliki nilai jual yang relative tinggi sehingga mayoritas sektor informal memilih sampah kertas untuk dikumpulkan.

\section{KESIMPULAN/RINGKASAN}

Kecamatan Sukun memiliki Laju timbulan sampah rumah tangga sebesar $0,4 \mathrm{~kg} /$ orang.hari. Laju timbulan sampah dengan area Bank Sampah sebesar 0,33 kg/orang.hari. Komposisi sampah sejenis sampah rumah tangga terdiri dari, dapat dikomposkan $67,82 \%$, plastik $8,82 \%$, kertas $10,88 \%$, kain $1,26 \%$, logam $1,27 \%$, kayu $0,9 \%$, kaca $0,1 \%$, diapers $5,42 \%$, B3 $1,3 \%$, karet $0,1 \%$ dan lainnya $0,1,92 \%$. Pengaruh Bank Sampah terhadap timbulan orang/hari berkurang sebesar $0,14 \mathrm{~kg} /$ orang/hari. Timbulan Sampah awalnya 66,6 ton per hari dengan adanya Bank Sampah Eksisting menjadi 65,9 ton per hari. Reduksi sampah yang dilakukan di TPS di Kecamatan Sukun sebesar $1.333 \mathrm{~kg}$ per hari.

\section{DAFTAR PUSTAKA}

[1] Kamalludin, "Studi Timbulan, Komposisi dan Karakteristik Sampah Domestik Kota Malang," 2013.

[2] B. S. Malang, Data Kecamatan Kota Malang Tahun 2013. Malang, 2015.

[3] Dinas Kebersihan dan Pertamanan Kota Malang, Pengelolaan Sampah di Kota Malang. Malang, 2103.

[4] Pemerintah Daerah, Dokumen Strategi Sanitasi Kota Malang. Malang, 2015.

[5] Devita, Peran Bank Sampah dalam Efektifitas Pengelolaan Sampah (Studi Kasus Bank Sampah Malang). 2011. 